\title{
Occurrence of methicillin-resistant staphylococci in the pig-production chain in Ibadan, Nigeria
}

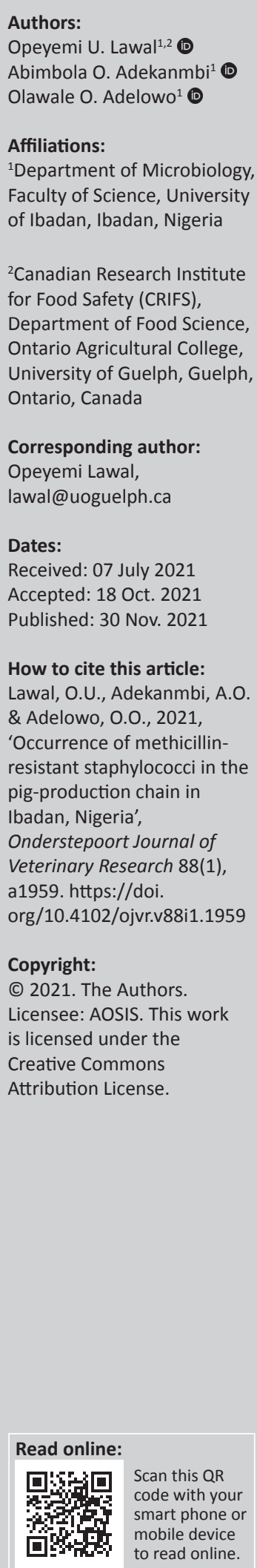

Staphylococcus species colonises humans and animals and is a major food contaminant with public health significance. Here, we assessed the occurrence of methicillin-resistant staphylococci (MRS) in the pig-production chain in Ibadan, Nigeria. Nares of 120 pigs and 10 farmers were sampled with sterile swabs whilst 54 pork samples were collected from a retail slaughterhouse. Staphylococcus species were isolated using enrichment, cefoxitin-aztreonam selective broth and Mannitol salt agar. Isolates were tested for susceptibility to cefoxitin $(30 \mu \mathrm{g})$, oxacillin $(1 \mu \mathrm{g})$ and vancomycin $(30 \mu \mathrm{g})$. Methicillin-resistant staphylococci isolates were characterised using conventional biochemical tests. From 184 samples, 364 staphylococcal isolates were obtained. Amongst the 54 pork samples, $44.0 \%$ were contaminated with Staphylococcus species. Overall, 9 (2.5\%) MRS were obtained and presumptively identified as Staphylococcus xylosus $(n=3)$, Staphylococcus sciuri $(n=3)$, Staphylococcus warneri $(n=2)$ and Staphylococcus cohnii $(n=1)$. There was no relationship between the prevalence of MRS between pigs and pig handlers in the farms, but Farm 2 had the highest frequency of $66.7 \%(p<0.05)$. Piglets had the highest prevalence of $66.7 \%(p<0.05)$ whilst MRS was absent in workers and pork samples. This study raises concerns about the cross-contamination of staphylococci in the food chain. Constant surveillance is imperative to ensure food safety.

Keywords: methicillin-resistant staphylococci; pigs; pork samples; colonisation; food contamination; food chain.

\section{Background}

Staphylococcus species colonises humans and animals and is one of the major food contaminants of public health importance (Becker, Heilmann \& Peters 2014). One of the challenges for controlling these bacteria is their development of resistance to antimicrobials including methicillin. Methicillin-resistant staphylococci (MRS) emerged in a variety of livestock animals, apparently through different mechanisms (De Boer et al. 2009). The close proximity amongst humans, livestock and antimicrobial use in animals presumably facilitates the emergence and spread of MRS (Bouchami et al. 2020). Methicillin-resistant staphylococci have been recovered from various retail products (Bouchami et al. 2020; De Boer et al. 2009) leading to an interest in MRS colonisation and infection in animals. Studies have shown that MRS could be transmitted between pigs (Verhegghe et al. 2013) and from pigs to their handlers (Bouchami et al. 2020). Actually, piglets are reported to be more vulnerable to MRS colonisation and infection because of the fragility of their immune system (Verhegghe et al. 2013).

Pork is one of the most consumed food commodities globally. Contamination of pork by staphylococci or MRS could result from cross-contamination from colonised pigs before slaughter or within the slaughterhouse by handlers that could end up in the food chain. However, handling contaminated meat could increase the risk of colonisation and infection in immunocompromised individuals (Bouchami et al. 2020). This study aimed to assess the contamination rate of retail pork samples and the occurrence of MRS along the pig-production chain in Ibadan, southwestern Nigeria.

\section{Methods}

\section{Description of the study site}

The study areas included five farms selected based on their proximity to densely populated communities located within the city of Ibadan, Oyo state, Nigeria. We employed a convenience sampling strategy wherein at least $30 \%$ of all categories of pigs and pig farmers resident in each farm at a time were sampled. Moreover, meats from an open-air slaughterhouse at Bodija market, Ibadan, where an average of 20 pigs per day are slaughtered were sampled (Table 1). 
TABLE 1: Summary of the sampling, antimicrobial use, Staphylococcus species, and methicillin-resistant isolates recovered in this study.

\begin{tabular}{|c|c|c|c|c|c|c|c|c|}
\hline Sample sites & Location & Antimicrobial use & Herd size & No of sample & $\begin{array}{l}\text { No positive } \\
\text { samples }\end{array}$ & $\begin{array}{l}\text { No of staphylococcal } \\
\text { isolates }\end{array}$ & $\begin{array}{l}\text { No of MRS } \\
\text { carrier }\end{array}$ & $\begin{array}{l}\text { Presumptive MRS } \\
\text { species }\end{array}$ \\
\hline Farm 1 & $\begin{array}{l}7^{\circ} 23^{\prime} 11^{\prime \prime} \mathrm{N}, \\
3^{\circ} 50^{\prime} 1^{\prime \prime} \mathrm{E}\end{array}$ & No record & $\begin{array}{l}\text { Pigs: } 42 \\
\text { Workers: } 2\end{array}$ & $\begin{array}{l}\text { Pigs: } 15 \\
\text { Workers: } 1\end{array}$ & 16 & 36 & 2 & $\begin{array}{l}\text { Staphylococcus } \\
\text { xylosus }(n=2)\end{array}$ \\
\hline Farm 2 & $\begin{array}{l}7^{\circ} 27^{\prime} 18^{\prime \prime} \mathrm{N}, \\
3^{\circ} 53^{\prime} 46^{\prime \prime} \mathrm{E}\end{array}$ & $\begin{array}{l}\text { Immunosol, levamisol, } \\
\text { nivamectin, envit, } \\
\text { oxytetracycline, pens } \\
\text { trep, tylophan, oxime, } \\
\text { pemacom }\end{array}$ & $\begin{array}{l}\text { Pigs }>200 \\
\text { Workers: }>10\end{array}$ & $\begin{array}{l}\text { Pigs: } 60 \\
\text { Workers: } 7\end{array}$ & 67 & 154 & 6 & $\begin{array}{l}\text { Staphylococcus } \\
\text { sciuri }(n=3), \\
\text { Staphylococcus } \\
\text { warneri }(n=2) \\
\text { Staphylococcus } \\
\text { cohnii }(n=1)\end{array}$ \\
\hline Farm 3 & $\begin{array}{l}7^{\circ} 38^{\prime} 36^{\prime \prime} \mathrm{N}, \\
4^{\circ} 43^{\prime} 13^{\prime \prime} \mathrm{E}\end{array}$ & $\begin{array}{l}\text { Oxime LA, B complex } \\
\text { Iron injection and } \\
\text { Ivomec }\end{array}$ & $\begin{array}{l}\text { Pigs: } 15 \\
\text { Workers } 4\end{array}$ & $\begin{array}{l}\text { Pigs: } 15 \\
\text { Workers } 0\end{array}$ & 15 & 30 & None & None \\
\hline Farm 4 & $\begin{array}{l}7^{\circ} 23^{\prime} 19^{\prime \prime} \mathrm{N}, \\
3^{\circ} 50^{\prime} 7^{\prime \prime} \mathrm{E}\end{array}$ & No record & $\begin{array}{l}\text { Pigs: } 40 \\
\text { Workers: } 3\end{array}$ & $\begin{array}{l}\text { Pigs: } 15 \\
\text { Workers } 0\end{array}$ & 15 & 30 & None & None \\
\hline Farm 5 & $\begin{array}{l}7^{\circ} 22^{\prime} 25.05^{\prime \prime} \mathrm{N}, \\
3^{\circ} 50^{\prime} 48.63^{\prime \prime} \mathrm{E}\end{array}$ & Oxime LA and Ivomec & $\begin{array}{l}\text { Pigs: } 42 \\
\text { Workers: } 4\end{array}$ & $\begin{array}{l}\text { Pigs: } 15 \\
\text { Workers: } 2\end{array}$ & 17 & 42 & 1 & $\begin{array}{l}\text { Staphylococcus } \\
\text { xylosus }\end{array}$ \\
\hline Total & NA & NA & NA & 184 & 154 & 364 & 9 & NA \\
\hline
\end{tabular}

NA, not applicable; MRS, methicillin-resistant staphylococci.

\section{Sample collection}

Nares of 120 pigs and 10 pig handlers were sampled using a sterile swab. Pork samples were collected once every fortnight from 10 pigs for five weeks. A total of 140 nasal swabs and 54 pork samples were collected. Samples were transported on ice to the laboratory for analysis (Table 1).

\section{Bacterial isolation and characterisation}

Isolation was performed as described previously (Vestergaard et al. 2012) using a three-step procedure. Briefly, swab sticks and $25 \mathrm{~g}$ of meat sample were inoculated in $225 \mathrm{~mL}$ peptone water (Oxoid) supplemented with $10 \mathrm{~mL}$ 6.5\% $\mathrm{NaCl}$ and incubated at $37^{\circ} \mathrm{C}$ for $18-24 \mathrm{~h}$. A $1 \mathrm{~mL}$ overnight culture was transferred unto tryptone soya broth (TSB, Oxoid) supplemented with $4 \mathrm{mg} / \mathrm{L}$ cefoxitin and $75 \mathrm{mg} / \mathrm{L}$ aztreonam and incubated at $37^{\circ} \mathrm{C}$ for $18-24 \mathrm{~h}$. A total of $10 \mu \mathrm{L}$ overnight TSB culture was streaked on mannitol salt agar (Oxoid) and incubated at $37{ }^{\circ} \mathrm{C}$ for $24-48 \mathrm{~h}$. The distinct, creamy to yellow colonies showing halo zones, which represent presumptive mannitol fermenting staphylococcal isolates, were subjected to preliminary biochemical tests, namely Gram staining, catalase, oxidase, DNase, blood haemolysis, urease production, l-arginine, gelatin hydrolysis, sugar fermentation and tube coagulase tests, as well as osmotolerance assays.

\section{Antibiotics susceptibility testing}

This was determined by the disk diffusion method according to Clinical and Laboratory Standards Institute (CLSI) guideline (CLSI 2015). Briefly, three colonies from an overnight culture were suspended in $5 \mathrm{~mL}$ of sterile normal saline. Optical density was adjusted to 0.5 McFarland standard, and sterile swab sticks were used to evenly spread the inocula over the entire surface of Mueller-Hilton Agar (Oxoid) plates supplemented with $4 \%$ sodium chloride. Antibiotic disks, namely novobiocin
$(5 \mu \mathrm{g})$, cefoxitin $(30 \mu \mathrm{g})$, oxacillin $(1 \mu \mathrm{g})$, and vancomycin $(30 \mu \mathrm{g})$, were placed on the Mueller-Hilton agar plate and incubated at $37^{\circ} \mathrm{C}$ for $24 \mathrm{~h}$. The diameter of the zone of growth inhibition around each disc was measured, and the results were interpreted using the CLSI guideline (CLSI 2015).

\section{Statistical analysis}

Descriptive analyses were initially performed. Microsoft Excel Spreadsheet was used for data processing. Frequency of MRS amongst groups was compared using one-way analysis of variance (ANOVA) with Bonferroni post-test using GraphPad InStat Version 3.00 for Windows 95. Association was deemed significant at $p<0.05$.

\section{Ethical considerations}

Ethical approval was obtained from the University of Ibadan review board (reference: UI/EC/13/0332).

\section{Results}

\section{Study farms and antimicrobial usage}

The five farms selected for this study were involved in pig production but lack accurate history of the type and quantity of antimicrobials used on the farms. Although the farm workers admitted to a regular use of antimicrobial as a feed additive and as prophylaxis, only three farms provided the necessary information to confirm this. Farm 2 uses immunosol (an immunomodulator), nivamectin (an antiparasitic) and oxytetracycline (an antibiotic), whereas Farms 3 and 5 use oxime LA, ivomec (antiparasitic) and B complex iron injection (Table 1).

\section{High contamination rate of the pig production chain by Staphylococcus species}

Using three-step method, all the samples recovered from pigs and pig handlers were positive for mannitol-positive 
Staphylococcus species. This is not surprising because the sampled site is the ecological niche for some of the staphylococcal species. However, $44 \%(n=24 / 54)$ of the pork samples were contaminated with mannitol-positive Staphylococcus species. Overall, 364 staphylococcal isolates were recovered from 184 samples (Table 1).

\section{Low occurrence of methicillin resistance amongst staphylococcal isolates recovered in pig-production chain}

In spite of using cefoxitin ( $4 \mathrm{mg} / \mathrm{L})$ to select for MRS, the antibiotics susceptibility testing yielded a low prevalence of MRS, as only 9 isolates $(2.5 \%, 9 / 364)$ were methicillin resistant (Table 1). These isolates were obtained from nine different pigs from three farms suggesting an overall MRS pig colonisation rate of $7.5 \% \quad(n=9 / 120$; Table 2$)$. Methicillin-resistant staphylococci were not recovered from workers or pork samples, and none of the isolates was found to be resistant to vancomycin. MRS were presumptively identified using biochemical tests as four coagulase-negative staphylococcal species, namely Staphylococcus sciuri $(n=3)$, Staphylococcus xylosus $(n=3)$, Staphylococcus warneri $(n=2)$ and Staphylococcus cohnii $(n=1$; Table 2). It is noteworthy that the great majority of the MRS were recovered from Farm $2(n=6,66.7 \%, p<0.05)$ and from piglets $(n=6,66.7 \%, p<0.05)$. No MRS was obtained from Farms 3 and 4 and from pork samples (Figure 1; Table 1).

TABLE 2: Distribution of methicillin-resistant staphylococci among the sample groups.

\begin{tabular}{|c|c|c|c|c|}
\hline Sample groups & $\begin{array}{l}\text { No of } \\
\text { samples }\end{array}$ & $\begin{array}{c}\text { No of } \\
\text { staphylococcal } \\
\text { isolates }\end{array}$ & $\begin{array}{l}\text { No of } \\
\text { MRS } \\
\text { carrier }\end{array}$ & Presumptive MRS species \\
\hline \multirow[t]{2}{*}{ Piglets } & 50 & 95 & 6 & $\begin{array}{l}\text { Staphylococcus cohnii }(n=1) \text {, } \\
\text { Staphylococcus xylosus }(n=1) \text {, }\end{array}$ \\
\hline & & & & $\begin{array}{l}\text { Staphylococcus sciuri }(n=2) \text {, } \\
\text { Staphylococcus warneri }(n=2)\end{array}$ \\
\hline Growers & 50 & 97 & 2 & $\begin{array}{l}\text { Staphylococcus sciuri, } \\
\text { Staphylococcus xylosus }\end{array}$ \\
\hline Breeders & 20 & 40 & 1 & Staphylococcus xylosus \\
\hline Workers & 10 & 60 & None & None \\
\hline Pork samples & 54 & 72 & None & None \\
\hline
\end{tabular}

MRS, methicillin-resistant staphylococci.

\section{Discussion}

Microbial contamination along the food chain poses a great threat to food safety and public health. In this study, we assessed the contamination of pork samples in a community market in Ibadan, southwest Nigeria, and the occurrence of MRS along the pig-production chain. Only nine samples were positive for MRS, all of which were from pigs, suggesting an overall MRS pig colonisation rate of $7.5 \%$, a value that is comparable to previous studies (Peng et al. 2019). Contrarily, a study (Verstappen et al. 2017) reported a higher prevalence of MRS (20\%) in livestock pigs. The great majority of the MRS $(n=6 / 9)$ were from piglets, an observation that reiterates piglets to have the propensity to harbour antibiotic-resistant bacteria because of their immune system fragility (Verhegghe et al. 2013). Alternatively, the sow could be the source of these MRS pre-weaning period or possibly may be acquired from the environment.

Surprisingly, the antimicrobial used in the farms studied were mostly similar and amongst those recommended for use in animal husbandry (Doyle, Hartmann \& Wong 2011). Whilst, the use of oxytetracycline in animal husbandry is reported to drive increased antimicrobial resistance, particularly MRS (Doyle et al. 2011), we could not establish this link in the study.

The overall frequency of MRS was low, as only $2.5 \%$ of the 364 mannitol-fermenting Staphylococcus species obtained were MRS. All the MRS isolates obtained were coagulase negative whilst none was found to be coagulase positive. This could be as a result of competition for site colonisation amongst staphylococci found in such environment (Tulinski et al. 2012). Amongst the nine MRS recovered, the most common species were $S$. sciuri ( $n$ $=3)$ and $S$. xylosus $(n=3)$, whilst others were $S$. warneri $(n=2)$ and S. cohnii $(n=1)$. A similar study conducted in pig farms also recovered methicillin-resistant strains of these species in addition to Staphylococcus lentus (Rattanamuang, Butr-Indr \& Anukool 2013). Staphylococcus sciuri colonises the skin and nares of humans and animals (Shittu et al. 2006) and is associated with

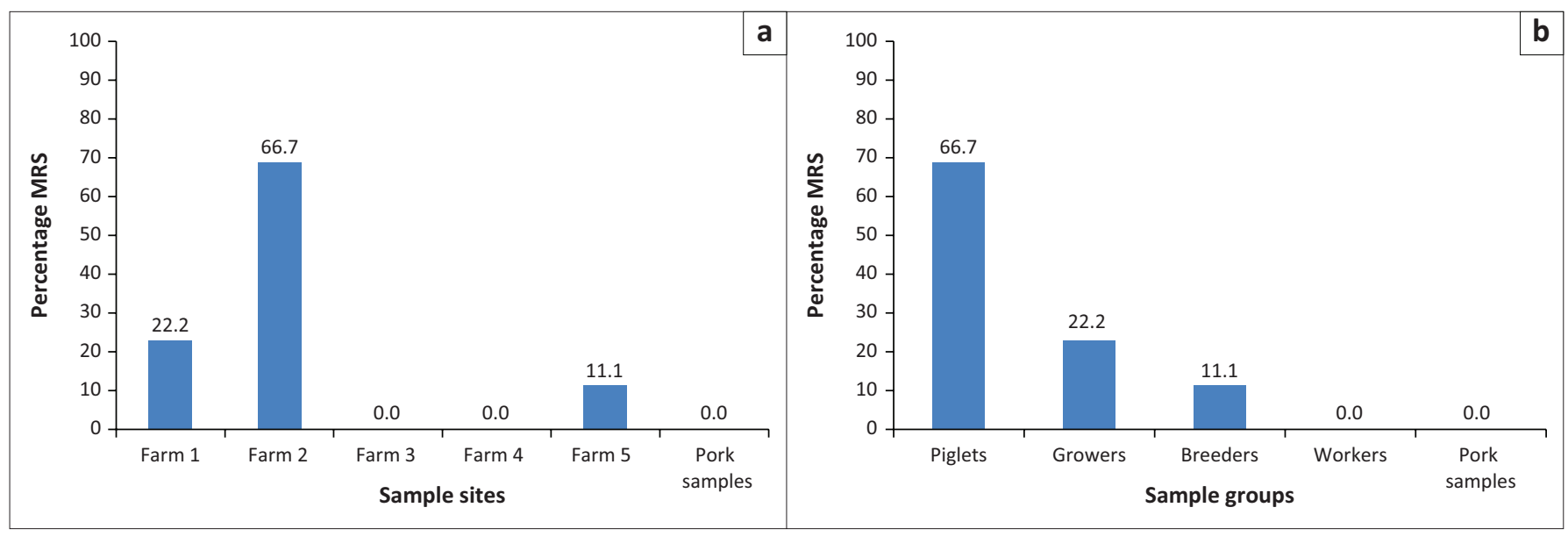

MRS, methicillin-resistant staphylococci.

FIGURE 1: Occurrence of methicillin-resistant staphylococci (MRS) along the pig-production chain in Ibadan. (a) Distribution of methicillin-resistant staphylococci in different sample sites. (b) Distribution of methicillin-resistant staphylococci in different sample groups. 
human infections including urinary tract infections (UTI), endocarditis, peritonitis and wound infections (Couto et al. 2000). It could also be implicated in fatal exudative epidermitis in piglets (Chen et al. 2007). Staphylococcus warneri colonises the skin of both animals and humans and occasionally causes septicaemia, endocarditis, osteomyelitis and other types of infections occurring in immunocompromised individual or patients with invasive treatment procedure. In humans, S. xylosus could be implicated in UTI and more rarely, in endocarditis, pyelonephritis or pneumonia (Beckeret al. 2014). Staphylococcus cohnii is an opportunistic pathogen found colonising human skin in only small numbers. The colonisation of S. cohnii in hospital environments has been previously reported, with almost all isolates identified as methicillin resistant (Heilmann, Ziebuhr \& Becker 2019).

Despite the absence of MRS in the retail pork samples investigated, the high contamination of these products by mannitol-positive staphylococci $(44 \%)$ could be of public health concern. This rate is comparable to those reported previously (Bouchami et al. 2020). Understandably, most staphylococci are part of human normal flora (Becker et al. 2014), but their presence in retail meat products suggests a cross-contamination phenomenon, most likely from human or the environment. Hence, a stricter hygienic programme would be appropriate to enforce and promote food safety practices.

\section{Conclusion}

This report assessed the antimicrobial use, occurrence of MRS in pig farms and explored the extent of contamination of retail pork samples. Although this study showed a low occurrence of MRS in the samples studied, the high contamination of pork samples by Staphylococcus species is of great concern. Proper monitoring and surveillance programmes are recommended for the early detection of staphylococcal foodborne outbreaks.

\section{Acknowledgements}

The authors appreciate all the farm workers for their support and voluntary participation in this study.

\section{Competing interests}

The authors declare that they have no financial or personal relationships that may have inappropriately influenced them in writing this article.

\section{Authors' contributions}

O.U.L. carried out the experiments, analysed the data and wrote the first draft of the manuscript. O.U.L., A.O.A. and O.O.A. were involved in the analyses of the results. O.U.L. and O.O.A. designed the study. O.O.A. supervised the study. All authors read, revised and approved the final version of the manuscript.

\section{Funding information}

The research received no specific grant from any funding agency in the public, commercial or not-for-profit sectors.

\section{Data availability}

The authors confirm that the data supporting the findings of this study are available within the article.

\section{Disclaimer}

The views and opinions expressed in this article are those of the authors and do not necessarily reflect the official policy or position of any affiliated agency of the authors.

\section{References}

Becker, K., Heilmann, C. \& Peters, G., 2014, 'Coagulase-negative staphylococci', Clinical Microbiology Reviews 27(4), 870-926. https://doi.org/10.1128/ CMR.00109-13

Bouchami, O., Fraqueza, M., Faria, N.A., Alves, V., Lawal, O.U., De Lencastre, H., et al., 2020 'Evidence for the dissemination to humans of methicillin-resistant Staphylococcus aureus ST398 through the pork production chain in Portugal', Microorganims 8(1892), 1-16. https://doi.org/10.3390/microorganisms 8121892

Chen, S., Wang, Y., Chen, F., Yang, H., Gan, M. \& Zheng, S.J., 2007, 'A highly pathogenic strain of Staphylococcus sciuri caused fatal exudative epidermitis in piglets', PLoS One 2(1), 1-6. https://doi.org/10.1371/journal.pone.0000147

CLSI, 2015, Performance standards for antimicrobial susceptibility testing; Twentyfifth informational supplement, CLSI document M100-S25, Clinical and Laboratory Standards Institute, Wayne, PA.

Couto, I., Sanches, I.S., Sá-Leão, R. \& De Lencastre, H., 2000, 'Molecular characterization of Staphylococcus sciuri strains isolated from humans', Journal of Clinical Microbiology 38(3), 1136-1143. https://doi.org/10.1128/jcm.38.3.1136-1143.2000

De Boer, E., Zwartkruis-Nahuis, J.T.M., Wit, B., Huijsdens, X.W., De Neeling, A.J. Bosch, T. et al., 2009, 'Prevalence of methicillin-resistant Staphylococcus aureus in meat', International Journal of Food Microbiology 134(1-2), 52-56. https://doi. org/10.1016/j.ijfoodmicro.2008.12.007

Doyle, M.E., Hartmann, F.A. \& Wong, A.C.L., 2011, White paper on sources of methicillin-resistant Staphylococcus aureus (MRSA) and other methicillin-resistant staphylococci: Implications for our food supply, FRI Food Safety Reviews, Food Research Institute, UW-Madison.

Heilmann, C., Ziebuhr, W. \& Becker, K., 2019, 'Are coagulase-negative staphylococci virulent?', Clinical Microbiology and Infection 25, 1071-1080. https://doi. org/10.1016/j.cmi.2018.11.012

Peng, P., Baldry, M., Gless, B.H., Bojer, M.S., Espinosa-Gongora, C., Baig, S.J., Andersen, P.S. et al., 2019, 'Effect of co-inhabiting coagulase negative staphylococci on $S$. aureus agr quorum sensing, host factor binding, and biofilm formation', Frontiers in Microbiology 10(2212), 1-14. https://doi.org/10.3389/fmicb.2019.02212

Rattanamuang, M., Butr-Indr, B. \& Anukool, U., 2013, 'Livestock-associated methicillinresistant coagulase-negative staphylococci in pig in Lamphun Province, Thailand, carrying Type-IX SCCmec element', The Bulletin of Chiang Mai Associated Medical Sciences 46(3), 250-259.

Shittu, A., Lin, J., Morrison, D. \& Kolawole, D., 2006, 'Identification and molecular characterization of mannitol salt positive, coagulase-negative staphylococci from nasal samples of medical personnel and students', Journal of Medical Microbiology 55(3), 317-324. https://doi.org/10.1099/jmm.0.46072-0

Tulinski, P., Fluit, A.C., Wagenaar, J.A., Mevius, D., Van De Vijver, L., Duim, B. et al., 2012, 'Methicillin-resistant coagulase-negative staphylococci on pig farms as a reservoir of heterogeneous staphylococcal cassette chromosome mec elements', Applied and Environmental Microbiology 78(2), 299-304. https://doi. org/10.1128/AEM.05594-11

Verhegghe, M., Pletinckx, L.J., Crombé, F., Weyenberg, S. Van, Haesebrouck, F., Butaye, P. et al., 2013, 'Cohort study for the presence of livestock-associated MRSA in piglets: Effect of sow status at farrowing and determination of the piglet colonization age', Veterinary Microbiology 162(2-4), 679-686. https://doi. org/10.1016/j.vetmic.2012.09.014

Verstappen, K.M., Willems, E., Fluit, A.C., Duim, B., Martens, M. \& Wagenaar, J.A., 2017, 'Staphylococcus aureus nasal colonization differs among pig lineages and is associated with the presence of other staphylococcal species', Frontiers in Veterinary Science 4(JUN), 1-6. https://doi.org/10.3389/fvets.2017.00097

Vestergaard, M., Cavaco, L.M., Sirichote, P., Unahalekhaka, A., Dangsakul, W. Svendsen, C.A. et al., 2012, 'Sccmec type IX element in methicillin resistant Staphylococcus aureus spa type t337 (CC9) isolated from pigs and pork in Thailand', Frontiers in Microbiology 3(MAR), 1-4. https://doi.org/10.3389/ fmicb.2012.00103 